\title{
The economic burden of cancers attributable to smoking in Korea, 2014
}

\author{
Thi Xuan Trinh Nguyen', Minji Han', Jin-Kyoung Oh',
}

\begin{abstract}
INTRODUCTION Associations between smoking, cancer and mortality are well established. Although cancer mortality rates have decreased in recent years, the economic burden of smoking-related cancers continues to increase. This study investigates the economic costs of cancers related to smoking in Korea in 2014. METHODS Cancer patients were identified through National Health Insurance Services medical claims with ICD-10 cancer codes. We multiplied the costs by the population attributable fraction for each type of cancer and calculated direct and indirect costs, where direct costs comprise direct medical and non-medical costs of inpatients and outpatients, and indirect costs include estimates of future income loss due to premature death, productivity loss during hospitalization and outpatient visits, and job loss.

RESULTS In 2014, there were 79297 smoking-related cancer patients, accounting for $8.47 \%$ of all Korean cancer cases for that year. The direct cost of cancers due to smoking was approximately 595 million USD, whereas indirect costs were much higher, at nearly 2.2 billion USD. The average expenditure of a typical patient was 34815 USD. Lung, liver and stomach cancers were most prevalent and represented the most significant share of the economic burden, whereas the largest per-patient spending was for pancreatic, liver, and lung cancers. Lung, liver and stomach cancers had the highest economic impact on men, while lung, liver and ovarian cancers had the most significant economic impact on women. CONCLUSIONS It is imperative that more stringent steps be taken to reduce the huge economic burden of cancers linked to smoking.
\end{abstract}

ABBREVIATIONS IARC: International Agency for Research on Cancer, PAF: population attributable fraction, NHIS: National Health Insurance Services, ICD-10: International Statistical Classification of Diseases and Related Health Problem 10th Revision, GDP: Gross Domestic Product, DALYs: Disability-Adjusted-Life-Years, WHO: World Health Organization, FCTC: Framework Convention on Tobacco Control.

\section{AFFILIATION \\ 1 Department of Cancer Control and Population Health, National Cancer Center Graduate School of Cancer Science and Policy, Goyang, Republic of Korea 2 National Cancer Control Institute, National Cancer Center, Goyang, Republic of Korea}

\section{CORRESPONDENCE TO}

Jin-Kyoung Oh. Department of Cancer Control and Population Health, National Cancer Center Graduate School of Cancer Science and Policy, 323 Ilsan-ro, Ilsandong-gu, Goyang-si, Gyeonggi-do 410-769, Republic of Korea.

E-mail: jkoh@ncc.re.kr

\section{KEYWORDS}

cancer, smoking, economic burden, Korea

Received: 31 October 2018 Revised: 12 December 2018 Accepted: 6 January 2019

\section{INTRODUCTION}

Smoking is associated with a variety of diseases and poses a major public health threat. Tobacco smoking, the most common form of smoking, encompasses over 4000 chemicals, of which more than 70 are known to be carcinogenic ${ }^{1}$. Causal relationships between cigarette smoking, increased all-cause mortality, and cancer-specific mortality are well established $^{2}$. Based on present consumption patterns, approximately 450 million adult smoking-related deaths will occur between 2000 and $2050^{3}$; half of the cases are predicted to die between the ages of 30 and 69 years. Although the number of smokers experienced a strikingly large increase over recent years as a result of global population growth ${ }^{4}$, since 1980 smoking prevalence has declined sharply in men and women worldwide. In particular, from 1990 to 2015 global smoking exposure decreased by more than $25 \%{ }^{5}$. Despite the decreased exposure, smoking still plays a major part in the Disability-Adjusted-Life- 
Years (DALYs) outcome ${ }^{5}$. Intensive efforts have been produced in the world's fight against tobacco since MPOWER was first deployed to help implement the World Health Organization's Framework Convention on Tobacco Control (WHO FCTC), with around two-thirds of countries (121 of 194) - consisting of $63 \%$ of the global population - starting to put at least one MPOWER measure into practice at the greatest level of achievement ${ }^{6}$. Although cancers and overall mortality from smoking have decreased significantly in highly developed countries, they are set to rise worldwide unless current smokers, most of whom live in low- and middle-income countries, stop smoking before or during middle age. The detrimental effect of smoking on society and healthcare system economies is substantial ${ }^{7}$; medical expenses arising from smoking-attributed diseases reached $5.7 \%$ of global healthcare spending in 2012 , which is equal to $1.8 \%$ of the world's gross domestic product (GDP). In some developing countries, smoking-related healthcare spending accounted for $40 \%$ of all healthcare spending, which underscores the overwhelming burden these countries carry ${ }^{8}$.

In Korea, the smoking rate among men is relatively high compared to other developed countries, even though it declined from $66.3 \%$ in 1998 to $40.7 \%$ in $2016^{9}$. The smoking rate among women was $6.4 \%$ in 2016 and has not changed significantly since 1998. To reduce smoking prevalence, Korea started to promote smoking ban policies in 1995 and efforts to reinforce and expand these programs have continued ${ }^{10}$. After Korea ratified the FCTC in 2005, the required policies incrementally strengthened tobacco control. According to the monitoring MPOWER in 2017 and the national progress report on the implementation of the FCTC in 2018, Korea has strengthened tobacco control policies, including tobacco tax increases, mass media campaigns, pictorial warnings on tobacco packs, smoke-free bars and restaurants, and reimbursement for smoking cessation services provided by healthcare facilities. However, the price of cigarettes remains low considering the nation's income level, and tobacco advertisements, promotion and sponsorship are only partially restricted. Workplace smoke-free policies are limited to large companies. Only monitoring of tobacco control policies and smoking cessation services are at a high level in Korea ${ }^{6,11,12}$.

Tobacco smoke was ranked as the third leading cause of DALYs in Korea in $2013^{13}$. Cancer, one of the diseases most initiated by smoking, is a leading cause of death in Korea and has a high incidence rate $\left(259\right.$ cases per 100000 persons in 2014) ${ }^{14}$. The negative health impact of smoking can be measured by quantifying smoking-associated illnesses, premature mortality, and productivity losses in monetary terms ${ }^{15}$. In Korea, several studies have been conducted to examine the burden of active and passive smokingattributable diseases; however, most of them employed the DALY measure to express disease burden ${ }^{10,16-18}$. Two studies have examined the economic burden of smoking-associated diseases ${ }^{19,20}$, one of which focused specifically on smoking-associated cancer in $2008^{20}$. However, cancer incidence and mortality have changed in recent years; all-cancer mortality has decreased since 2002 while cancer incidence increased until 2012 then began to decrease ${ }^{14}$. In this study, we examined more recent data to update estimates regarding the economic burden of smoking-related cancers in Korea.

\section{METHODS}

\section{Smoking-related cancer types}

Major cancers attributable to smoking were identified from the International Agency for Research on Cancer (IARC) evaluation on carcinogenicity ${ }^{1}$ and previous studies ${ }^{20,21}$ and defined according to the International Statistical Classification of Diseases and Related Health Problems 10th Revision (ICD10): cancers of the oral cavity (C00-C09), pharynx (G10-G14), esophagus (G15), stomach (G16), colorectum (C18-C20), liver (C22), pancreas (C25), larynx (C32), lung (C33-C34), cervix uteri (C53), ovary (C56), kidney (C64), and bladder (C67). This study used the gender-specific smoking-attributable fractions (SAF) for each cancer type in the Korean population from a published study ${ }^{21}$. In brief, sexand cancer-specific population-attributable fractions (PAF) were estimated using the prevalence of ever smoking and secondhand smoking in 1989 among Korean adults, respectively, and the relative risks were estimated from the meta-analysis of studies performed in the Korean population for the case of ever smoking and in the Asian population for passive smoking. National cancer incidence data from the Korea Central Cancer Registry and national cancer mortality data from Statistics Korea for the year 2009 were used to estimate the cancer cases and deaths 
attributable to tobacco smoking ${ }^{21}$.

The total economic cost of cancers attributed to smoking was measured by multiplying the cost of each cancer site by its respective SAF according to the formula:

Smoking-attributable costs $=$ Total costs of cancer sites $\times S A F$

\section{Data source}

Health insurance claims data provided by the National Health Insurance Services (NHIS) were used to estimate prevalence and direct medical costs of smoking-attributable cancers. The NHIS is a mandatory single payer insurance that provides benefits for medical services. All South Korean citizens must either be enrolled in the NHIS (97\% of the population) or must be a recipient of medical aid $(3 \%)^{22}$. The NHIS database contains information on medical aid subjects as well; therefore, it contains information on the Korean population. Currently, the NHIS maintains and stores national records for healthcare use and prescriptions. The NHIS claims data contain details on the cost of care, medical institution attended, income distribution, and residential information for all insurance subscribers ${ }^{23}$.

To estimate direct non-medical costs and indirect costs, data from diverse sources were used including the Korea Health Panel Survey (KHPS) ${ }^{24}$, cause of death statistics and life tables provided by Statistics $\mathrm{Korea}^{25}$, and employment rates and wage data provided by the Ministry of Employment and Labor ${ }^{26}$ (See Supplementary Table).

This study used anonymous secondary data and was exempted from review by the Institutional Review Board of the National Cancer Center, Korea (NCC2017-0131). Consent was waived.

\section{Estimation of economic burden}

The economic burden of cancers associated with smoking was evaluated using a prevalence-based approach that targeted existing and newly diagnosed cancer patients. Patients who visited or were hospitalized in medical institutions with smokingrelated cancer as a primary diagnosis in 2014 were included in the analysis. In the claims data, the special code V193, which indicates a confirmed cancer diagnosis for expanded benefit coverage, was used to define cancer cases. Given the time-lag between initiating a smoking habit and cancer development, the study population included only those aged 20 years and older ${ }^{10,17}$.

The total economic burden of smoking-attributed cancers was calculated as the sum of direct costs and indirect costs.

\section{Total costs $=$ Direct costs + Indirect costs}

\section{Direct costs}

Direct costs are costs incurred during the period of medical treatment and include both medical and nonmedical costs. The former includes expenditures for inpatient and outpatient medical treatment, and the latter includes transportation costs for travel to inpatient or outpatient centers, and caregiver costs. Indirect costs comprise productivity loss due to premature death, productivity loss incurred during absences following hospitalization and outpatient visits, and job loss arising from unemployment after a cancer diagnosis.

Direct medical care costs were obtained from the NIHS 2014 medical claims records of existing and newly diagnosed smoking-attributable cancers. Noncovered healthcare costs were set at $19.9 \%$, the rate reported by a previous study ${ }^{27}$. Direct non-medical care costs were calculated from transportation costs for all inpatient/outpatient visits plus total payments to caregivers. The one-way transportation fee per inpatient/outpatient visit was determined to be 13.7 and 3.7 USD, respectively, by analyzing raw data from the $2014 \mathrm{KHPS}^{28}$. These figures were multiplied by the number of visits to obtain transportation costs. Based on the 2014 KHPS, the estimated daily wage of caregivers was 57.7 USD and had a use rate of $67 \%$ among inpatients only ${ }^{28}$. Caregivers' costs were divided into costs incurred during inpatient and outpatient care. Inpatient care costs were calculated under the assumption that each inpatient was accompanied by a healthcare guardian for the entire day; thus, the cost was determined by combining the daily caregiver payment with the number of days hospitalized and the nursing use rate. In addition, costs paid by patients aged 65 years or older were calculated by multiplying the number of outpatient visit days by one-third of the daily caregivers' wage (See Supplementary Table).

Formulae given below have been adapted from Lee et al. ${ }^{29}$. The direct costs, DC, were calculated from: 


$$
\begin{aligned}
\mathrm{DC}= & \sum_{\mathrm{i}} \sum_{\mathrm{j}} \sum_{\mathrm{y}}\left\{(1+\mathrm{a}) I P_{i j y}+(1+\mathrm{a}) O P_{i j y}\right\} \times P A F_{i y}+ \\
& \sum_{\mathrm{i}} \sum_{\mathrm{j}} \sum_{\mathrm{y}}\left\{\left(I V_{i j y} \times 2 T I V\right)+\left(O V_{i j y} \times 2 T O V\right)\right\} \times P A F_{i j}+ \\
& \sum_{\mathrm{i}} \sum_{\mathrm{j}} \sum_{\mathrm{y}}\left\{\left(I V_{i j y} \times C G R \times C\right)+\left(O V_{i j y} \times C G R / 3\right)\right\} \\
& \times P A F_{i y .} .
\end{aligned}
$$

where, the summations are over gender (i), age (j) and cancer type (y), IP is total treatment amount for inpatients in NHIS data, OP is total treatment amount for outpatients in NHIS data, $a$ is the proportion between non-coverage and coverage rate (in this study, $a=19.9 / 80.1$ ), IV is the number of days of inpatient visits, $\mathrm{OV}$ is number of days of outpatient visits, TIV is cost per one-way trip to hospitals among inpatients, TOV is cost per one-way trip to hospitals among outpatients, CGR is caregivers' average wage per day, $\mathrm{C}$ is use rate, $\mathrm{OV}^{\prime}$ ' is number of days of outpatient visits among those aged 65 years and above and PAF is population attributable fraction.

\section{Indirect costs}

Indirect costs were broken down into future income loss, productivity loss and job loss:

\section{Indirect costs $=$ Future income loss + Productivity loss + Job loss}

To identify costs associated with premature death, a human capital approach was applied, which considered the potential earnings for each deceased person from the year of their death until the end year of their average life expectancy. Productivity loss following premature deaths was calculated using data from Cause of Death Statistics ${ }^{25}$; employment rates and annual average salaries by sex and age were provided by the Ministry of Employment and Labor $^{26}$. Future expected incomes were converted into current values by applying a discount rate of $3 \%$ per year. To calculate productivity loss resulting from medical institution visits and hospitalization, the total number of outpatient visits and inpatient admission days were collected from the NHIS claims data. These values were combined with age- and sexspecific employment rates and monthly wage data. Job loss was described as productivity loss due to unemployment resulting from a cancer diagnosis. This was estimated by identifying the number of pre-existing and newly diagnosed smoking-attributed cancer cases along with the overall job loss rate for cancer patients in Korea, which was $47 \%{ }^{30}$. These figures were then aggregated with employment rates and daily wage data by age and gender to determine the costs arising from unemployment following a cancer diagnosis (Supplementary Table).

The future income loss, FIL, was calculated from:

$$
\mathrm{FIL} \mathrm{=} \sum_{(1 \mathrm{i}} \sum_{\mathrm{j}} \sum_{\mathrm{t}} \sum_{\mathrm{k}=1}^{\mathrm{n}}\left\{D_{i j t} \times D P A F_{i y} \times\left(Y W_{i j(t+k)} \times E_{i j(t+k)}\right) /\right.
$$

where, the summation now includes over age at death $(\mathrm{t})$, years $(\mathrm{k})$ with maximum value $\mathrm{n}$ the difference between age at death and life expectancy of cohort, D is number of deaths, DPAF is death population attributable fractions, $\mathrm{YW}$ is yearly wage, $\mathrm{E}$ is employment rate, and $\mathrm{r}$ is discount rate. The productivity loss, PL, was calculated from:

$$
\mathrm{PL}=\sum_{\mathrm{i}} \sum_{\mathrm{j}} \sum_{\mathrm{y}}\left\{\left(I V_{i j y}+O V_{i j y} / 2\right) \times P A F_{i y} \times E_{i j} \times D W_{i j}\right\}
$$

where DW is daily wage. The job loss, JL, was calculated from:

$$
\mathrm{JL}=\sum_{\mathrm{i}} \sum_{\mathrm{j}} \sum_{\mathrm{y}}\left(N_{i j y} \times Y W_{i j} \times E_{i j} \times L \times P A F_{i y}\right)
$$

where $\mathrm{N}$ is number of prevalent cancer cases, $\mathrm{YW}$ is yearly wage, and $\mathrm{L}$ is job loss rate.

A one-way sensitivity analysis was performed by varying the annual discount rate from undiscounted $(0 \%)$, to discounted (3\%), and more discounted (5\%), for productivity loss due to premature death. The analyses were conducted using SAS software (SAS Institute Inc., Cary, NC, USA) and Excel 2013. The costs were converted from KRW to USD using the 2014 exchange rate $(1 \mathrm{USD}=1091.85 \mathrm{KRW})^{31}$.

\section{RESULTS}

In 2014, there were 79297 smoking-attributable cancer cases, accounting for $8.47 \%$ of the total cancer patients in Korea. Among these patients, the majority of cancer cases due to smoking (nearly $61 \%$ ) were in the 60 to 79 years age groups (Table 1). Furthermore, around one-third of total cancer cases attributed to smoking had stomach cancer, followed by lung and liver cancers. This finding did not differ by gender.

The economic burden from smoking-attributable cancers in Korea in 2014 was approximately 2.76 billion USD, of which around $35.8 \%$ of the total costs 
Table 1. The number of smoking-related cancer patients, according to age in years, in Korea, 2014

\begin{tabular}{|c|c|c|c|c|c|c|c|c|c|}
\hline Cancer type & Gender & $20-29$ & $30-39$ & $10-19$ & $50-59$ & $60-69$ & $70-79$ & 80 & Total \\
\hline \multirow[t]{2}{*}{ Oral cavity } & Men & 44 & 101 & 287 & 698 & 664 & 447 & 111 & 2351 \\
\hline & Women & 22 & 42 & 76 & 129 & 104 & 107 & 50 & 529 \\
\hline \multirow[t]{2}{*}{ Pharynx } & Men & 16 & 47 & 134 & 369 & 405 & 304 & 74 & 1349 \\
\hline & Women & $<10$ & $<10$ & 24 & 37 & 21 & 19 & $<10$ & 118 \\
\hline \multirow[t]{2}{*}{ Esophagus } & Men & $<10$ & $<10$ & 70 & 556 & 1080 & 1090 & 242 & 3045 \\
\hline & Women & $<10$ & $<10$ & $<10$ & $<10$ & $<10$ & $<10$ & $<10$ & 14 \\
\hline \multirow[t]{2}{*}{ Stomach } & Men & 24 & 354 & 2031 & 5828 & 7271 & 6237 & 1604 & 23348 \\
\hline & Women & $<10$ & 31 & 109 & 181 & 186 & 217 & 91 & 817 \\
\hline \multirow[t]{2}{*}{ Colorectum } & Men & $<10$ & 17 & 71 & 230 & 310 & 274 & 80 & 983 \\
\hline & Women & $<10$ & $<10$ & $<10$ & $<10$ & $<10$ & $<10$ & $<10$ & $<10$ \\
\hline \multirow[t]{2}{*}{ Liver } & Men & $<10$ & 127 & 907 & 3082 & 3043 & 2096 & 521 & 9786 \\
\hline & Women & $<10$ & 10 & 40 & 145 & 215 & 234 & 92 & 738 \\
\hline \multirow[t]{2}{*}{ Pancreas } & Men & $<10$ & 19 & 104 & 326 & 482 & 507 & 159 & 1599 \\
\hline & Women & $<10$ & $<10$ & $<10$ & $<10$ & 10 & 14 & $<10$ & 40 \\
\hline \multirow[t]{2}{*}{ Larynx } & Men & $<10$ & 14 & 101 & 691 & 1232 & 1158 & 301 & 3498 \\
\hline & Women & $<10$ & $<10$ & $<10$ & 13 & 15 & 28 & 10 & 71 \\
\hline \multirow[t]{2}{*}{ Lung } & Men & 25 & 131 & 710 & 3073 & 6371 & 7919 & 2491 & 20721 \\
\hline & Women & $<10$ & 14 & 64 & 213 & 283 & 317 & 143 & 1036 \\
\hline \multirow[t]{2}{*}{ Cervix uteri } & Men & 0 & 0 & 0 & 0 & 0 & 0 & 0 & 0 \\
\hline & Women & $<10$ & 12 & 24 & 25 & 16 & 11 & $<10$ & 93 \\
\hline \multirow[t]{2}{*}{ Ovary } & Men & 0 & 0 & 0 & 0 & 0 & 0 & 0 & 0 \\
\hline & Women & 20 & 34 & 84 & 134 & 80 & 44 & 12 & 408 \\
\hline \multirow[t]{2}{*}{ Kidney } & Men & $<10$ & 51 & 147 & 261 & 234 & 163 & 35 & 898 \\
\hline & Women & $<10$ & $<10$ & $<10$ & $<10$ & $<10$ & $<10$ & $<10$ & $<10$ \\
\hline \multirow[t]{2}{*}{ Bladder } & Men & 16 & 90 & 350 & 1155 & 2125 & 2758 & 1253 & 7748 \\
\hline & Women & $<10$ & $<10$ & $<10$ & 14 & 23 & 38 & 25 & 107 \\
\hline Subtotal & & 200 & 1111 & 5344 & 17171 & 24173 & 23985 & 7312 & 79297 \\
\hline
\end{tabular}

were contributed by lung cancers, with the second and third largest costs associated with liver and stomach cancers. The same pattern of the top three cancer types held for men, whereas for women, lung, liver and ovarian cancers were associated with the highest expenditures for smoking-attributed cancers. The total cost for an average smoking-related Korean cancer patient in 2014 was 34815 USD. Smokingrelated pancreatic cancer cases incurred the highest costs, with 72720 USD spent per case, followed by liver and lung cancers at 53719 and 45459 USD, respectively (Table 2 ).

The direct costs of cancers attributable to smoking were found to be nearly 595 million USD. In particular, lung, liver and stomach cancers were associated with the largest direct-cost expenditure, irrespective of gender. Noticeably, in men, lung, stomach and liver cancers were responsible for most of the direct healthcare costs, with nearly $70 \%$ of direct costs associated with these cancer types, whereas in women, around two-thirds of the total direct costs were associated with lung, liver and ovarian cancers. Nearly $90 \%$ of the estimated direct costs were from direct medical costs, with the remaining $10 \%$ from non-medical costs (e.g. travel costs to medical institutions and caregivers' costs) (Table 2).

The indirect costs of smoking-attributed cancers were determined to be nearly three times higher than the direct costs, reaching approximately 2.2 billion USD. As with direct costs, the top three most costly smoking-related cancers in terms of indirect costs were lung, liver, and stomach cancers, both overall and for men. In women, lung cancer took the lead for the highest indirect costs, followed by ovarian and liver cancers (Table 2).

Nearly half of the total economic impact of smoking-related cancers stemmed from future income loss, followed by indirect costs due to job loss after 
Table 2. Total costs of smoking-related cancers by cancer type and sex, in Korea, 2014 (Thousand USD)

\begin{tabular}{|c|c|c|c|c|c|c|c|c|c|c|c|}
\hline \multirow[b]{2}{*}{$\begin{array}{l}\text { Cancer } \\
\text { sile }\end{array}$} & \multirow[b]{2}{*}{ Gender } & \multicolumn{4}{|c|}{ Direet costs } & \multicolumn{4}{|c|}{ Indirect costs } & \multirow[b]{2}{*}{ Total } & \multirow[b]{2}{*}{$\begin{array}{c}\text { Per } \\
\text { patient }\end{array}$} \\
\hline & & Vedical & Transportation & Caregiver & Subtotal & $\begin{array}{l}\text { Future } \\
\text { income } \\
\text { loss }\end{array}$ & $\begin{array}{l}\text { Productivity } \\
\text { loss }\end{array}$ & $\begin{array}{l}\text { Job } \\
\text { loss }\end{array}$ & Subtotal & & \\
\hline \multirow[t]{2}{*}{ Oral cavity } & Men & 17975 & 216 & 1585 & 19776 & 48443 & 5330 & 26916 & 80689 & 100464 & 42.734 \\
\hline & Women & 3103 & 39 & 310 & 3452 & 726 & 333 & 2170 & 3229 & 6681 & 12.619 \\
\hline \multirow[t]{2}{*}{ Pharynx } & Men & 14245 & 172 & 1421 & 15837 & 27622 & 4195 & 14073 & 45890 & 61727 & 45.764 \\
\hline & Women & 995 & 13 & 102 & 1110 & 372 & 130 & 549 & 1051 & 2160 & 18.346 \\
\hline \multirow[t]{2}{*}{ Esophagus } & Men & 29212 & 333 & 3305 & 32850 & 69939 & 6595 & 21014 & 97549 & 130398 & 42.825 \\
\hline & Women & 111 & $<10$ & 16 & 131 & $<10$ & $<10$ & 35 & 53 & 184 & 12.963 \\
\hline \multirow[t]{2}{*}{ Stomach } & Men & 86783 & 1185 & 9711 & 97680 & 216060 & 16587 & 220536 & 453183 & 550863 & 23.594 \\
\hline & Women & 3017 & 41 & 398 & 3455 & 271 & 234 & 2757 & 3262 & 6718 & 8.221 \\
\hline \multirow[t]{2}{*}{ Colorectum } & Men & 5563 & 76 & 576 & 6216 & 5834 & 1386 & 8704 & 15924 & 22140 & 22.525 \\
\hline & Women & $<10$ & $<10$ & $<10$ & $<10$ & 389 & $<10$ & $<10$ & 389 & 389 & NA \\
\hline \multirow[t]{2}{*}{ Liver } & Men & 88227 & 866 & 7660 & 96753 & 348640 & 1179 & 104903 & 454723 & 551476 & 56.356 \\
\hline & Women & 6227 & 64 & 686 & 6976 & 4968 & 20 & 1903 & 6891 & 13867 & 18.781 \\
\hline \multirow[t]{2}{*}{ Pancreas } & Men & 18471 & 223 & 2265 & 20960 & 79454 & 5099 & 12843 & 97396 & 118355 & 74.015 \\
\hline & Women & 427 & $<10$ & 63 & 494 & 218 & 35 & 89 & 342 & 837 & 20.923 \\
\hline \multirow[t]{2}{*}{ Larynx } & Men & 18842 & 262 & 2180 & 21284 & 14800 & 4097 & 25315 & 44212 & 65497 & 18.723 \\
\hline & Women & 447 & $<10$ & 72 & 526 & 35 & 30 & 166 & 231 & 757 & 10.619 \\
\hline \multirow[t]{2}{*}{ Lung } & Men & 196276 & 2349 & 21547 & 220172 & 579578 & 36586 & 129603 & 745767 & 965939 & 46.615 \\
\hline & Women & 8904 & 106 & 1071 & 10080 & 9604 & 737 & 2721 & 13062 & 23142 & 22.337 \\
\hline \multirow[t]{2}{*}{ Cervix uteri } & Men & 0 & 0 & 0 & 0 & 0 & 0 & 0 & 0 & 0 & NA \\
\hline & Women & 435 & 7 & 47 & 489 & 2322 & 71 & 491 & 2884 & 3372 & 36.437 \\
\hline \multirow[t]{2}{*}{ Ovary } & Men & 0 & 0 & 0 & 0 & 0 & 0 & 0 & 0 & 0 & NA \\
\hline & Women & 3610 & 54 & 461 & 4126 & 2552 & 598 & 2091 & 5242 & 9368 & 22.942 \\
\hline \multirow[t]{2}{*}{ Kidney } & Men & 3062 & 36 & 283 & 3381 & 4907 & 877 & 11029 & 16813 & 20195 & 22.498 \\
\hline & Women & $<10$ & $<10$ & $<10$ & $<10$ & 198 & $<10$ & $<10$ & 198 & 198 & NA \\
\hline \multirow[t]{2}{*}{ Bladder } & Men & 25327 & 448 & 3343 & 29117 & 21685 & 4968 & 49379 & 76032 & 105149 & 13.572 \\
\hline & Women & 382 & $<10$ & 62 & 451 & 133 & 23 & 203 & 359 & 810 & 7.586 \\
\hline Total & & 531642 & 6509 & 57165 & 595316 & 1438760 & 89119 & 637490 & 2165370 & 2760686 & 34.815 \\
\hline
\end{tabular}

NA: not available because of very few patients.

Figure 1. Proportions of cost components (\%)

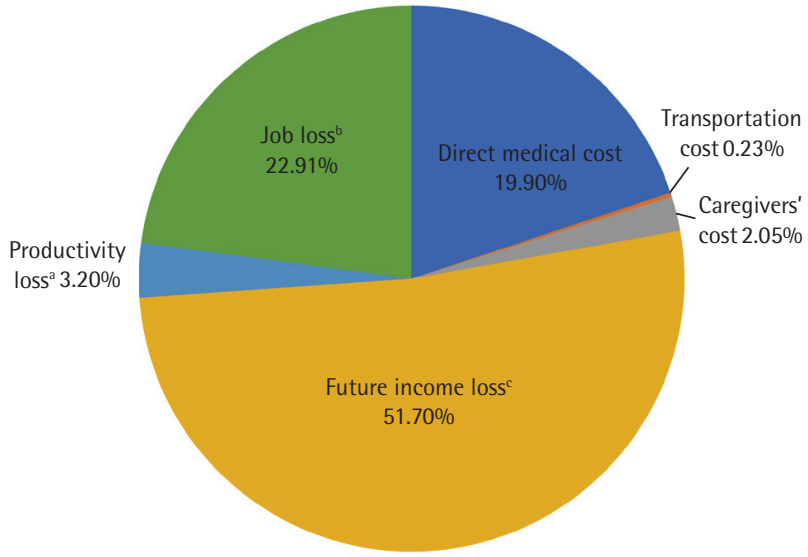

a Productivity loss: income loss due to morbidity (hospitalization/outpatient visits). b Job loss: income loss due to unemployment post cancer diagnosis.

c Future income loss: income loss due to premature death.
Table 3. Sensitivity analysis of economic burden of smoking-related cancers, applying discount rates from $0 \%$ to $5 \%$ (Thousand USD)

\begin{tabular}{|l|c|c|c|}
\hline & \multicolumn{3}{c|}{ Discoumint rates } \\
\hline Indirect costs & 2527206 & 2165370 & 1997761 \\
\hline Total costs & 3122522 & 2760686 & 2593077
\end{tabular}

cancer diagnosis and direct medical costs, at around $23 \%$ and $20 \%$, respectively (Figure 1 ).

Sensitivity analysis was conducted applying discount rates of $0 \%, 3 \%$ and $5 \%$. The economic burden increased by $12 \%$ with the no discount applied, reaching 3.12 billion USD, whereas the economic burden decreased to 2.59 billion USD when the $5 \%$ discount rate was applied (Table 3 ). 


\section{DISCUSSION}

The economic burden of cancers attributed to smoking in Korea in 2014 was approximately 2.76 billion USD, of which indirect costs were found to be significantly higher than direct costs by as much as 3.64 times. Previous studies also showed that indirect costs were more burdensome, reporting indirect costs as 2 to 3 times direct $\operatorname{costs}^{20,32}$. Furthermore, the economic burden of cancers attributable to smoking were $0.2 \%$ of the national GDP and about $1.19 \%$ of the total national healthcare expenditure in $2014^{22,33}$. It is worth noting that smoking-related cancers represented a less significant economic burden in 2014 compared to 2008 with 3104 million USD spent after adjusting for inflation, possibly resulting from a decreasing trend of cancer incidence and mortality ${ }^{14}$.

When the economic burdens of men and women are considered together, lung, liver and stomach cancers were the leading cause of economic costs. Among the major cancers in men, the costs of lung cancer were highest, followed by liver and stomach cancers, whereas in women the highest costs were associated with lung, liver, and ovarian cancers. These results are understandable in that lung, liver and stomach cancers have taken the lead in Korean mortality rates ${ }^{34}$. In the $\mathrm{Oh}$ et al. ${ }^{20}$ study, which estimated the economic burden of smokingassociated cancers in 2008, the top four cancers were (in decreasing importance) lung, liver, colorectal, and stomach cancers. The most noticeable difference is that in the current study stomach cancer replaced colorectal cancer as the third leading cause of cancer mortality, and colorectal cancer only accounted for a small proportion of total costs $(0.82 \%)$ in our study population. One possible explanation for this is the difference in study methods and epidemiological characteristics used by each study. In our study, we employed the PAF of smoking in the Korean population from the Park et al. ${ }^{21}$ study, which reported that around $0.8 \%$ of all colorectal cancer cases are attributed to smoking regardless of sex, while the $\mathrm{Oh}$ et al. study calculated the PAF according to Levin's formula, using relative risk from Japanese research ${ }^{20}$. This insignificant PAF value (i.e. $0.8 \%$ ) is the primary reason for the small contribution of colorectal cancer to total costs incurred in our study.

It is interesting to note that the cost burden for men was nearly 39.3 times higher than for women in each cancer category, except of course for cervical and ovarian cancers. This is consistent with previous studies that reported total costs for men as being much higher than for women ${ }^{20}$. One reason for this is a huge difference in the PAFs for incidence and mortality that were used to calculate costs. According to the Park et al. ${ }^{21}$ study, there is a big gap in the PAF for smoking-related cancer incidence in men (20.9) compared with women (2.1) and a similar pattern in PAF for mortality. Also, our study results suggest that the number of smoking-attributed cancer cases was nearly 19 times higher in men (75325) compared to women (3972).

According to a study that systematically reviewed costs of smoking-related diseases, smoking-attributed illnesses were responsible for $1.5-6.8 \%$ of the national health expenditures and $0.22-0.88 \%$ of GDP for a given country ${ }^{35}$. Various studies investigating the economic burden of cigarette smoking-related cancers have been carried out in the United States and other high-income countries ${ }^{36,37}$. Given that smoking prevalence and cigarette consumption has been increasing dramatically in developing countries, where the burden of tobacco-related cancers is projected to increase by about $69.6 \%{ }^{38}$, several studies have been conducted to highlight the rapidly rising burden of smoking-related diseases in those countries. For example, the economic costs of smoking in 2011 accounted for $0.97 \%$ of GDP in Vietnam, representing $5.76 \%$ of the government healthcare budget ${ }^{39}$, whereas in China, 3.1\% of national healthcare expenditure was associated with smoking in $2000^{40}$.

In this study, job loss was included as an indispensable element of indirect costs. Although most studies that calculated the economic burden of smoking-related diseases did not take into consideration lost income associated with unemployment after cancer diagnosis, in Korea, job loss is a critical issue because of its large contribution to total costs. According to our study findings, job loss after a cancer diagnosis accounted for more than onefifth of the overall smoking-associated cancer costs. It is very important to note the impact of cancer on patients' working lives, since 5 -year survival rates and mortality rates among Korean cancer patients have shown gradual signs of improvement ${ }^{41}$. One study reported that of 5396 patients engaged at baseline, a significant proportion (47\%), were unemployed 
during a 3-year follow-up period ${ }^{30}$, suggesting that job loss drives a substantial portion of indirect costs.

Unlike other studies, our participants were identified by the V193 diagnostic code, which, in South Korea confers Expanded Benefit Coverage for patients with severe illnesses such as cancer and myocardial infarction. These expanded benefits helped to diminish extensive healthcare expenditures that might have occurred without the expanded coverage ${ }^{42,43}$. In contrast, several studies estimating the economic burden of cancers in Korea identified cancer patients by hospital admissions and number of outpatient visits. To be included in these studies, patients had to experience at least one inpatient admission and three outpatient visits ${ }^{44}$. One exception was a study on the economic costs of metabolic syndrome-related cancers ${ }^{45}$, for which special diagnostic codes were employed. Results of that study suggested that there was a slight difference in total costs when patients were identified by a frequencyof-visits definition versus the special diagnostic code definition. On that basis we can predict that there might be a modest effect in the total costs calculated in our study.

\section{Limitations}

One limitation of our study concerns the possible overestimation of productivity loss resulting from premature death, which could result from using the human capital approach. This approach has been criticized for its assumption that a worker cannot be replaced even if unemployment is very high ${ }^{46}$. Nonetheless, the human capital approach is still one of the most frequently used methods to determine indirect costs of diseases. A second limitation stems from a potential underestimate of outpatient pharmaceutical costs, which cannot be verified in the NHIS claims data, and the costs for alternative and complementary medicine, which were not included in the estimates. Another possible shortcoming derives from the lack of several item cost estimations, of which might be program costs for prevention and early detection of smoking-related cancers, presentism and costs for cigarette purchases. Finally, the total cost of smoking-related cancers might also have been underestimated for several potential reasons: 1) only primary cancer diagnoses were included in this study; 2) cancers of the nasal cavity and accessory sinuses, ureter, and myeloid leukemia, which are known as a smoking-related cancers, were not included in the analysis because these cancers have low incidence and never reported Korean specific SAF; and 3) a positive association between smoking and breast cancer has been suggested but not included in this study because of lack of SAF.

Despite these limitations, this study provides valuable updated information on the economic burden of cancers associated with smoking in Korea.

\section{CONCLUSIONS}

Despite the early initiation of tobacco control policy in Korea, the economic burden of cancers attributable to smoking remains high because cancer can take years to develop after the initial smoking exposure. In addition, the prevalence of smoking among young adults and women is increasing in Korea. Therefore, it is crucial that intense efforts are made to develop strict smoking control programs.

\section{REFERENCES}

1. International Agency for Research on Cancer. Volume 100E - Personal habits and indoor combustions. Lyon: IARC; 2012

2. National Center for Chronic Disease P, Health Promotion Office on S, Health. Reports of the Surgeon General. The Health Consequences of Smoking-50 Years of Progress: A Report of the Surgeon General. Atlanta, GA: Centers for Disease Control and Prevention (US); 2014.

3. Jha P. Avoidable global cancer deaths and total deaths from smoking. Nat Rev Cancer. 2009;9:655-664. doi:10.1038/nrc2703

4. Ng M, Freeman MK, Fleming TD, et al. Smoking prevalence and cigarette consumption in 187 countries, 1980-2012. JAMA. 2014;311(2):183-192. doi:10.1001/jama.2013.284692

5. GBD 2015 Risk Factors Collaborators. Global, regional, and national comparative risk assessment of 79 behavioural, environmental and occupational, and metabolic risks or clusters of risks, 1990-2015: a systematic analysis for the Global Burden of Disease Study 2015. The Lancet. 2016;388:1659-1724. doi:10.1016/S0140-6736(16)31679-8

6. World Health Organization. WHO report on the global tobacco epidemic, 2017: monitoring tobacco use and prevention policies. Geneva: World Health Organization; 2017.

7. Chung CW, Wang JD, Yu CF, Yang MC. Lifetime medical expenditure and life expectancy lost attributable to smoking through major smoking related diseases in Taiwan. Tob Control. 2007;16(6):394-399. 
doi:10.1136/tc.2006.018986

8. Goodchild M, Nargis N, Tursan d'Espaignet E. Global economic cost of smoking-attributable diseases. Tob Control. 2018;27(1):58-64. doi:10.1136/tobaccocontrol-2016-053305

9. Korean Centers for Disease Control and Prevention, Korea Health Statistics 2016. Korea National Health and Nutrition Examination Survey. Osong: KCDC; 2018.

10. Ha BM, Yoon SJ, Lee HY, Ahn HS, Kim CY, Shin YS. Measuring the burden of premature death due to smoking in Korea from 1990 to 1999. Public Health. 2003;117(5):358-365. doi:10.1016/s0033-3506(03)00142-2

11. Lim MK, Cho HJ. Current status of tobacco control policies in Korea compared with international treaty and its implementation. J Korean Med Assoc. 2018;61(3):148156. doi:10.5124/jkma.2018.61.3.148

12. World Health Organization. FGTC Parties' reports: Republic of Korea. https://untobaccocontrol.org/impldb/ republic-of-korea/. Accessed December 7, 2018.

13. Institute of Health Metrics and Evaluation. GBD compare. https://vizhub.healthdata.org/gbd-compare/patterns. Accessed October 31, 2018.

14. Jung KW, Won YJ, Kong HJ, Lee ES. Cancer Statistics in Korea: Incidence, Mortality, Survival, and Prevalence in 2015. Cancer Res Treat. 2018;50(2):303-316. doi: $10.4143 /$ crt.2018.143

15. World Health Organization (WHO). Assessment of the Economic Costs of Smoking. Economics of Tobacco Toolkit. World Health Organization; 2011.

16. Zahra A, Cheong HK, Lee EW, Park JH. Burden of Disease Attributable to Secondhand Smoking in Korea. Asia Pac J Public Health. 2016;28(8):737-750. doi:10.1177/1010539516667779

17. Lee H, Yoon SJ, Ahn HS. Measuring the burden of major cancers due to smoking in Korea. Cancer Sci. 2006;97(6):530534. doi:10.1111/j.1349-7006.2006.00205.x

18. Zahra A, Cheong HK, Park JH. Burden of Disease Attributable to Smoking in Korea. Asia Pac J Public Health. 2017;29(1):47-59. doi:10.1177/1010539516675696

19. Kang HY, Kim HJ, Park TK, Jee SH, Nam CM, Park HW. Economic burden of smoking in Korea. Tob Control. 2003;12(1):37-44. doi:10.1136/tc.12.1.37

20. Oh IH, Yoon SJ, Yoon TY, et al. Health and economic burden of major cancers due to smoking in Korea. Asian Pac J Cancer Prev. 2012;13(4):1525-1531. doi:10.7314/apjcp.2012.13.4.1525

21. Park S, Jee SH, Shin HR, et al. Attributable fraction of tobacco smoking on cancer using populationbased nationwide cancer incidence and mortality data in Korea. BMC Cancer. 2014;14(1):406. doi:10.1186/1471-2407-14-406

22. National Health Insurance Service, Health Insurance Review \& Assessment Service. National Health Insurance Statistical Yearbook. Wonju; 2016.
23. Cheol Seong S, Kim YY, Khang YH, et al. Data Resource Profile: The National Health Information Database of the National Health Insurance Service in South Korea. Int J Epidemiol. 2017;46:799-800. doi:10.1093/ije/dyw253

24. Korea Health Panel Study. https://www.khp.re.kr:444/ eng/main.do. Accessed October 31, 2018.

25. Statistics Korea. Cause of Death Statistics in 2014. http://kostat.go.kr/portal/eng/pressReleases/ $8 / 10 /$ index. board? bmode $=$ read $\& b S e q=\&$ aSeq $=$ $349053 \&$ pageNo $=1 \&$ row Num $=10 \&$ navCount $=$ $10 \&$ currPg $=\&$ sTarget $=$ title\&sTxt. Accessed October 31, 2018.

26. Korea Ministry of Employment and Labor. Survey Report on Labor Conditions by Employment Type. 2015.

27. National Health Insurance Services. Survey on the Benefit Coverage Rate of National Health Insurance in 2014. 2014.

28. Korea Health Panel Study. https://www.khp.re.kr:444/ eng/main.do.

29. Lee S, Chung W, Hyun KR. Socioeconomic costs of liver disease in Korea. Korean J Hepatol. 2011;17(4):274-291. doi:10.3350/kjhep.2011.17.4.274

30. Park JH, Park EC, Park JH, Kim SG, Lee SY. Job loss and re-employment of cancer patients in Korean employees: a nationwide retrospective cohort study. J Clin Oncol. 2008;26(8):1302-1309. doi:10.1200/jco.2007.14.2984

31. Exchange Rates. Korean Won Rates for $12 / 31 / 2014$ US Dollar. https://www.exchange-rates.org/Rate/KRW/ USD/12-31-2014 2014. Accessed October 31, 2018.

32. Lee S, Chung W, Hyun KR. Socioeconomic costs of liver disease in Korea. Korean J Hepatol. 2011;17(4):274-291. doi:10.3350/kjhep.2011.17.4.274

33. South Korea GDP - Gross Domestic Product. https:// countryeconomy.com/gdp/south-korea?year=2014. Published 2014. Accessed October 31, 2018.

34. Jung KW, Won YJ, Oh CM, et al. Cancer Statistics in Korea: Incidence, Mortality, Survival, and Prevalence in 2014. Cancer Res Treat. 2017;49:292-305. doi: $10.4143 /$ crt.2017.118

35. Rezaei S, Akbari Sari A, Arab M, Majdzadeh R, Mohammad Poorasl A. Economic burden of smoking: a systematic review of direct and indirect costs. Med J Islam Repub Iran. 2016;30:397

36. Ruff LK, Volmer T, Nowak D, Meyer A. The economic impact of smoking in Germany. Eur Respir J. 2000;16(3):385390. doi:10.1034/j.1399-3003.2000.016003385.x

37. Nonnemaker J, Rostron B, Hall P, MacMonegle A, Apelberg B. Mortality and economic costs from regular cigar use in the United States, 2010. Am J Public Health. 2014;104(9):e86-91. doi:10.2105/ajph.2014.301991

38. Kristina SA, Endarti D, Thavorncharoensap M. Burden of cancer attributable to tobacco smoking in member countries of the Association of Southeast Asian Nations (ASEAN), 2012. Cancer Epidemiol. 2016;44:84-90. doi:10.1016/j.canep.2016.08.005 
39. Hoang Anh PT, Thu le T, Ross H, Quynh Anh N, Linh BN, Minh NT. Direct and indirect costs of smoking in Vietnam. Tob Control 2016;25:96-100. doi:10.1136/tobaccocontrol-2014-05182

40. Sung HY, Wang L, Jin S, Hu TW, Jiang Y. Economic burden of smoking in China, 2000. Tob Control 2006;15 Suppl 1:i5-11. doi:10.1136/tc.2005.015412

41. Jung KW, Won YJ, Oh CM, et al. Prediction of cancer incidence and mortality in Korea, 2015. Cancer Res Treat. 2015;47(2):142-148. doi:10.4143/crt.2015.066

42. National Law Information Center, Ministry of Government Legislation. http://www.law.go.kr/eng/engMain.do. Accessed October 31, 2018.

43. Health Insurance Review \& Assessment Service. http:// www.hira.or.kr/main.do. Accessed october31, 2018.

44. Seok Jun Yoon. A study on measuring and forecasting the burden of disease in Korea. 2015.

45. Kim D, Yoon SJ, Gong YH, et al. The Economic Burden of Cancers Attributable to Metabolic Syndrome in Korea. J Prev Med Public Health. 2015;48(4):180-187. doi:10.3961/jpmph.15.022

46. Jo C. Cost-of-illness studies: concepts, scopes, and methods. Clin Mol Hepatol. 2014;20(4):327-337. doi:10.3350/cmh.2014.20.4.327
CONFLICTS OF INTEREST

Authors have completed and submitted the ICMJE Form for Disclosure of Potential Conflicts of Interest and none was reported.

\section{FUNDING}

This study was supported by the National Cancer Center (NCC-1610410). The first author, NTXT, received funding from the 'International Cooperation \& Education Program (NCCRI-NCCI 52210-52211, 2018)' of the National Cancer Center, Korea.

\section{AUTHORS' CONTRIBUTIONS}

NTXT designed the study, analyzed data, interpreted the results and wrote the main manuscript text. MH analyzed the raw data. JKO participated in the study design, collected data and critically revised the whole manuscript. All authors read and approved the final manuscript.

\section{PROVENANCE AND PEER REVIEW}

Not commissioned; externally peer reviewed. 